University of Nebraska - Lincoln

DigitalCommons@University of Nebraska - Lincoln

\title{
Efficacy of Methyl Bromide for Control of Different Life Stages of Stored-Product Psocids
}

Christos G. Athanassiou

University of Thessaly, athanassiou@agr.uth.gr

M. Mahbub Hasan

Kansas State University

Thomas W. Phillips

Kansas State University, twp1@ksu.edu

M. Jamie Aikins

Kansas State University

James E. Throne

USDA-ARS, Manhattan, KS, james.throne@ars.usda.gov

Follow this and additional works at: https://digitalcommons.unl.edu/usdaarsfacpub

Athanassiou, Christos G.; Hasan, M. Mahbub; Phillips, Thomas W.; Aikins, M. Jamie; and Throne, James E., "Efficacy of Methyl Bromide for Control of Different Life Stages of Stored-Product Psocids" (2015).

Publications from USDA-ARS / UNL Faculty. 2049.

https://digitalcommons.unl.edu/usdaarsfacpub/2049

This Article is brought to you for free and open access by the U.S. Department of Agriculture: Agricultural Research Service, Lincoln, Nebraska at DigitalCommons@University of Nebraska - Lincoln. It has been accepted for inclusion in Publications from USDA-ARS / UNL Faculty by an authorized administrator of DigitalCommons@University of Nebraska - Lincoln. 


\title{
Efficacy of Methyl Bromide for Control of Different Life Stages of Stored-Product Psocids
}

\author{
CHRISTOS G. ATHANASSIOU, ${ }^{1,2,3}$ M. MAHBUB HASAN,${ }^{4,5}$ THOMAS W. PHILLIPS, ${ }^{4}$ \\ M. JAMIE AIKINS, ${ }^{4}$ AND JAMES E. THRONE ${ }^{3,6}$
}

\begin{abstract}
J. Econ. Entomol. 108(3): 1422-1428 (2015); DOI: 10.1093/jee/tov069
ABSTRACT The psocid species Liposcelis paeta Pearman, Liposcelis entomophila (Enderlein), Liposcelis decolor (Pearman), Liposcelis bostrychophila Badonnel (Psocoptera: Liposcelididae), and Lepinotus reticulatus Enderlein (Psocoptera: Trogiidae) were evaluated in laboratory bioassays to determine their susceptibility to six concentrations of methyl bromide $(0.027,0.113,0.280,0.393,0.452$, and $0.616 \mathrm{~g} / \mathrm{m}^{3}$ ) after $48 \mathrm{~h}$ of exposure at $27.5^{\circ} \mathrm{C}$. The life stages that were evaluated were adults (for all species), nymphs (for all species except Lep. reticulatus), and eggs (for L. entomophila, L. decolor, and L. bostrychophila). Adults and nymphs were very susceptible, and complete mortality was recorded at concentrations between 0.027 and $0.280 \mathrm{~g} / \mathrm{m}^{3}$. In contrast, eggs were by far more tolerant than adults and nymphs for all species tested. At $0.027 \mathrm{~g} / \mathrm{m}^{3}$, mortality did not exceed $53 \%$, while survival was high even at $0.113 \mathrm{~g} / \mathrm{m}^{3}$. Complete $(100 \%)$ egg mortality was recorded at $0.393 \mathrm{~g} / \mathrm{m}^{3}$ for L. decolor and at $0.452 \mathrm{~g} / \mathrm{m}^{3}$ for L. entomophila and L. bostrychophila; concentrations estimated to give $99 \%$ mortality for eggs of these three species were $0.710,1.044$, and $0.891 \mathrm{~g} / \mathrm{m}^{3}$, respectively. These results show that stored-product psocids are susceptible to methyl bromide, but concentrations of $\geq 0.452 \mathrm{~g} / \mathrm{m}^{3}$ should be used to control all life stages.
\end{abstract}

KEY WORDS methyl bromide, fumigant, Psocoptera, Liposcelis, Lepinotus

Psocids are emerging pests of stored products, and they can cause serious infestations especially in grains and amylaceous commodities (Nayak 2006, Nayak et al. 2014). Athanassiou et al. (2010a) reported that several psocid species are able to develop on sound grain kernels, despite the fact that, until recently, psocids were considered as secondary colonizers of stored grains. Opit and Throne (2008a) reported the ability of psocids to develop even at low relative humidity, which usually is not favorable for many other major stored-product insect pests. Psocids can rapidly multiply to extremely high population densities which are devastating for the product (Kučerová 2002, Athanassiou et al. 2014). For example, in laboratory experiments, Athanassiou et al. (2014) found that five females of Liposcelis bostrychophila Badonnel (Psocoptera: Liposcelididae) were able to produce $>250$ individuals after $70 \mathrm{~d}$ in a vial that

\footnotetext{
${ }^{1}$ Laboratory of Entomology and Agricultural Zoology, Department of Agriculture, Crop Production and Rural Environment, University of Thessaly, Phytokou str., 38446, N. Ionia Magnesia, Greece.

${ }^{2}$ Corresponding author, e-mail: athanassiou@agr.uth.gr.

${ }^{3}$ USDA, Agricultural Research Service, Center for Grain and Animal Health Research, 1515 College Avenue, Manhattan KS 665022736, USA.

${ }^{4}$ Department of Entomology, 123 W. Waters Hall, Kansas State University, Manhattan, KS 66506-4004, USA.

${ }^{5}$ Laboratory of Post-harvest Entomology, Department of Zoology, Rajshahi University, Rajshahi 6205, Bangladesh.

${ }^{6}$ Current address: USDA, Agricultural Research Service, Jan San Joaquin Valley Agricultural Sciences Center, 9611 S. Riverbend Ave., Parlier CA 93648, USA
}

contained only $5 \mathrm{~g}$ of wheat. Similar results have been reported for other psocid species, such as Liposcelis entomophila (Enderlein), Liposcelis paeta Pearman, Liposcelis decolor (Pearman), and Lepinotus reticulatus Enderlein (Psocoptera: Trogiidae) (Opit and Throne 2008a,b; Athanassiou et al. 2010a, 2014).

Stored-product psocids have a "natural tolerance" to several categories of insecticides that are used with success for the control of other key stored-product insect pests. In a screening of contact insecticides on wheat, rice, and maize, Athanassiou et al. (2009) reported that L. bostrychophila, L. paeta, and L. decolor were tolerant to spinosad and natural pyrethrum. Athanassiou et al. (2010b) reported that that five psocid species were tolerant to the insect growth regulator methoprene, even at dose rates that exceeded the label rate. Nayak et al. (1998) reported that the organophosphorous compounds chlorpyriphos-methyl and pirimiphosmethyl could not control L. entomophila and L. paeta. Opit et al. (2012) reported that several aerosols were not able to control major psocid pest species. Psocids also have been found to be tolerant to fumigant insecticides. For example, Nayak et al. (2003) and Nayak and Collins (2008) reported that eggs of L. bostrychophila were tolerant to the fumigant phosphine. Although there is considerable intraspecific variation, some psocid species are now considered to be tolerant to phosphine (Nayak et al. 2003, 2014). Athanassiou et al. (2012) tested sulfuryl fluoride under laboratory conditions for control of various life stages of major stored-product psocid pest species and reported that 
mortality of adults and nymphs was complete (100\%) after $48 \mathrm{~h}$ of exposure, even at dose rates that were lower than the label rate. In contrast, after the same exposure interval, complete egg mortality of L. paeta and $L$. decolor was achieved only at doses that exceeded the label dose, which clearly indicates that this fumigant has a poor ovicidal effect against Liposcelididae. Similarly, Bonjour et al. (2011) reported that psocid eggs were far more tolerant to ozone as compared to the mobile stages. Therefore, the withdrawal of methyl bromide, which has been completed in 2005 in developed countries and is expected to be completed in the beginning of 2015 in developing countries (United Nations Environment Programme [UNEP] 1998), leaves a serious gap in stored-product protection, as there are no alternatives that act like methyl bromide against difficult to control species or difficult to control life stages.

Based on the above, psocids should be considered as "difficult to control" for both fumigants and contact insecticides. Paradoxically, the information available for the efficacy of methyl bromide for the control of psocids is scarce (Pike 1994, Rajendran 1994), despite the fact that many studies illustrate that "novel fumigants" are not effective for these species. Moreover, the data available are focused only for some species, and on bioassay protocols that are based on population growth estimates, rather than separate species-life stage bioassays. For example, Pike (1994) used suppression of $L$. entomophila population as an indication that all life stages were killed after the application of methyl bromide. However, there are no data for the efficacy of methyl bromide against different life stages of most major stored-product psocid species. Despite the fact that methyl bromide is being banned for its environmental impact as an ozone-depleting substance (UNEP 1998), more data on effective lethal doses for control of psocids are important because methyl bromide will still be used for quarantine and preshipment treatments on commodities potentially infested with psocids. Hence, we evaluated the efficacy of methyl bromide against all life stages of several major stored-product psocid pest species.

\section{Materials and Methods}

Insects. Individuals of the psocid species L. paeta, L. entomophila, L. decolor, L. bostrychophila, and Lep. reticulatus were used in the tests. Psocids were reared on a mixture of $97 \%$ cracked wheat kernels, $2 \%$ Rice Krispies breakfast cereal, and $1 \%$ brewer's yeast at $30^{\circ} \mathrm{C}$ and $70 \%$ relative humidity $(\mathrm{RH}$; Opit and Throne 2008a). We followed the procedure described by Opit and Throne (2008a) to obtain individuals of standardized age for experimentation. Based on this technique, 30 female adults of unknown age of each species were left to oviposit for $3 \mathrm{~d}$ in 3.5-cm-diameter petri dishes containing $1 \mathrm{~g}$ of red-colored psocid diet, the parental females were then removed, and the eggs, nymphs, and adults produced were used in the tests. By following this technique, the eggs that were used in the bioassays were $1-3 \mathrm{~d}$ old. Nymphs used were at the Nland N2 stage, while adults were $<21 \mathrm{~d}$ old.
Insecticide. Methyl bromide (Meth-o-Gas 100, purity $100 \%$ ) was provided by Great Lakes Chemical Corporation (West Lafayette, IN) in a cylinder and stored at ambient conditions. Small quantities of methyl bromide were removed from the cylinder before each series of bioassays and transferred to a Tedlar (CEL Scientific Corp., Santa Fe Springs, CA) plastic bag.

Bioassays. Experiments were conducted at the Department of Entomology at Kansas State University. The experimental procedure was similar to that described by Athanassiou et al. (2012). Briefly, glass jars (10.3-liter capacity) were the fumigation chambers for these tests. These jars were airtight and equipped with a port in the center, which was covered with a rubber injection septum that was used for the introduction of the fumigant and sampling. There were three jars for each tested methyl bromide concentration, which were used as replicates. The methyl bromide concentrations evaluated were 0 (control), 0.027, 0.113, $0.280,0.393,0.452$, and $0.616 \mathrm{~g} / \mathrm{m}^{3}\left(1 \mathrm{~g} / \mathrm{m}^{3}=1 \mathrm{mg}\right)$ liter). The concentrations selected were based on preliminary experimentation that indicated that these concentrations were effective for the control of other stored-product insects. In all concentrations, the psocid species and life stages tested were adults of L. paeta, L. entomophila, L. decolor, L. bostrychophila, and Lep. reticulatus; nymphs of $L$. paeta, $L$. entomophila, L. decolor, and L. bostrychophila; and eggs of L. entomophila, L. decolor, and L. bostrychophila. All insects were introduced into the fumigation chambers in small cylindrical glass vials $(4.5 \mathrm{~cm}$ in height, $1.2 \mathrm{~cm}$ in diameter) before the introduction of methyl bromide (different vials for each species and life stage). The vials were placed with no lid in the jars, and the neck of the vial was covered with Fluon (polytetrafluoroethylene; Northern Products, Woonsocket, RI) to prevent psocids from escaping. There were 10 individuals (eggs, nymphs, or adults) in each vial. A small quantity of diet was added to each vial that contained eggs to avoid potential cannibalism. For each species-life stage combination, there was one vial for each jar. For the fumigation, the required quantity of methyl bromide was calculated and introduced separately into each jar through the rubber septum by using a gas-tight syringe after removal of an equivalent volume of air from the jar (Sekhon et al. 2010, Athanassiou et al. 2012). Conditions inside the jars were $27.5^{\circ} \mathrm{C}$ and $70 \% \mathrm{RH}$. The jars were opened $48 \mathrm{~h}$ later, and all vials were removed. Mortality was assessed the same day in vials that contained adults or nymphs. Vials containing eggs were incubated for $8 \mathrm{~d}$ under the aforementioned conditions, and then they were examined for hatching. Methyl bromide concentration within each jar was measured, as suggested by Sekhon et al. (2010), using gas chromatography-mass spectrometry to ensure that the average gas concentration was $\leq 10 \%$ different from the desired target concentration.

Data Analysis. Untreated control mortality was low $(<10 \%$ for adults and nymphs and $<30 \%$ for eggs).The data for each species and life stage were analyzed using 

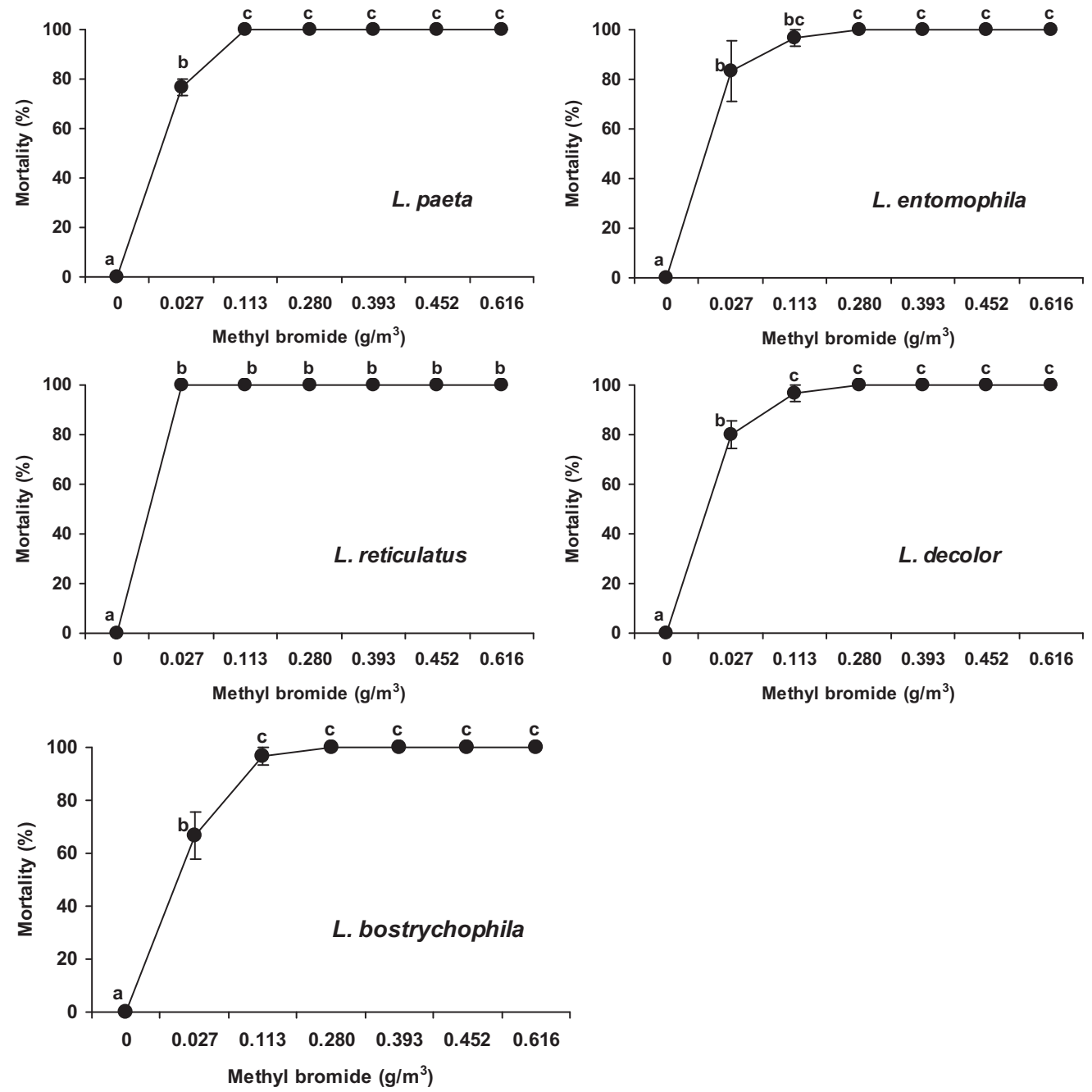

Fig. 1. Mortality (\% \pm SE) of adults of L. paeta, L. entomophila, L. decolor, L. bostrychophila, and Lep. reticulatus, after a 48-h exposure to methyl bromide. Within each species, means followed by the same letter are not significantly different (HSD test at 0.05; for L. paeta $F=879.0$, for L. entomophila $F=61.7$, for Lep. reticulatus $F=41.7$, for $L$. decolor $F=65.5$, and for L. bostrychophila $F=216.3$; in all cases $\mathrm{df}=6.14$ and $P<0.001$ ).

a one-way analysis of variance to determine the influence of gas concentration on mortality. Means were separated by the Tukey-Kramer honestly significant difference (HSD) test at $P \leq 0.05$. We report the results of probit analyses on the data only for eggs because the estimates of LC values for adults and nymphs were generally poor ( $100 \%$ mortality in most dose rates) because the slope of the mortality curve was so steep that there were generally only a few concentrations that could be included in the analyses, despite the large number of concentrations included in our experimental design.

\section{Results}

Adult Mortality. Among the psocid species tested, Lep. reticulatus was the most susceptible to methyl bromide, as mortality was $100 \%$ even at the lowest concentration of $0.027 \mathrm{~g} / \mathrm{m}^{3}$ (Fig. 1). For all other species, adult mortality at the lowest concentration ranged between 67 and $83 \%$. At $0.113 \mathrm{~g} / \mathrm{m}^{3}$, mortality was $100 \%$ for L. paeta, but mortality was between 95 and $100 \%$ for the other Liposcelis species tested. Mortality was $100 \%$ at $0.280 \mathrm{~g} / \mathrm{m}^{3}$ for all species tested (Fig. 1).

Nymph Mortality. Nymphs were generally more susceptible than adults (Fig. 2). Mortality ranged between 87 and $93 \%$ at the lowest concentration of $0.027 \mathrm{~g} / \mathrm{m}^{3}$, but was $100 \%$ at $0.113 \mathrm{~g} / \mathrm{m}^{3}$ for all species tested (Fig. 2).

Egg Mortality. Eggs were less susceptible than adults or nymphs. Mortality did not exceed $47 \%$ for any of the species tested at the lowest concentration of $0.027 \mathrm{~g} / \mathrm{m}^{3}$ (Fig. 3). Egg mortality was only slightly increased at $0.113 \mathrm{~g} / \mathrm{m}^{3}$ and ranged between 67 

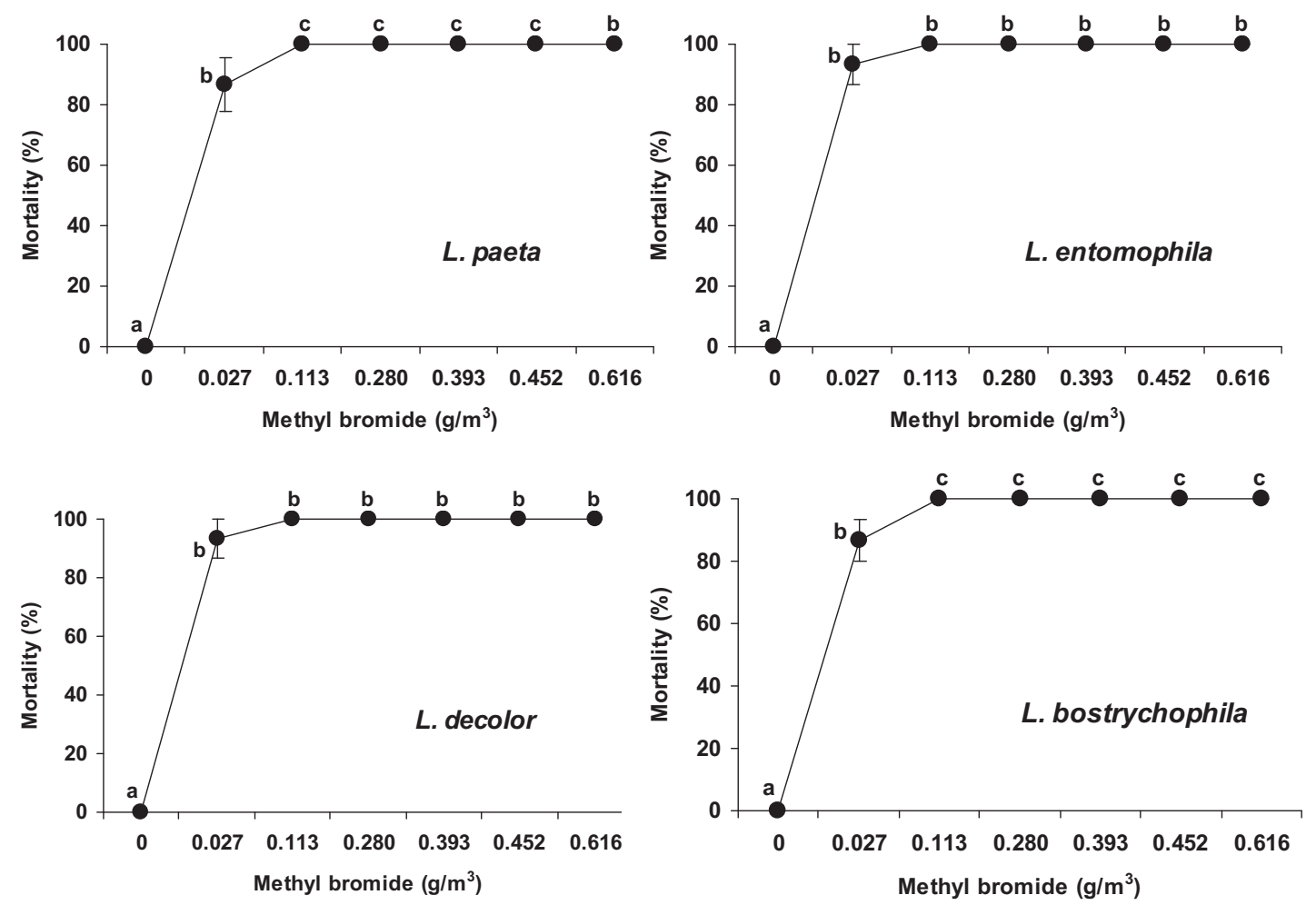

Fig. 2. Mortality (\% \pm SE) of nymphs of L. paeta, L. entomophila, L. decolor, and L. bostrychophila after a 48-h exposure to methyl bromide. Within each species, means followed by the same letter are not significantly different (HSD test at 0.05 ; for L. paeta $F=125.1$, for $L$. entomophila $F=221.0$, for $L$. decolor $F=221.0$, and for $L$. bostrychophila $F=219.0$; in all cases $\mathrm{df}=6.14$ and $P<0.001)$.

(for L. entomophila) and $77 \%$ (for L. decolor). At higher dose rates, egg mortality of the three species tested was $\sim 90 \%$ (Fig. 3). L. decolor was the most susceptible species at the egg stage, given that mortality was $100 \%$ at $0.393 \mathrm{~g} / \mathrm{m}^{3}$, while for the other two species, $100 \%$ mortality was achieved only at the two highest concentrations. The highest LC values were found for L. entomophila, but LC values were rather similar for all species (Table 1).

\section{Discussion}

By comparing the results of the present study with the data presented by Athanassiou et al. (2012) for the efficacy of sulfuryl fluoride for control of psocids by using the same protocol (48-h exposure), it becomes evident that methyl bromide is much more effective than sulfuryl fluoride for the control of these species. In the sulfuryl fluoride study, we showed that both adults and nymphs of major stored-product psocid pest species were highly susceptible to that fumigant. Our current results show that mobile life stages of psocids were also extremely susceptible to methyl bromide, given that mortality was high even at low concentrations. In contrast, eggs were more tolerant to methyl bromide than nymphs or adults. In our bioassays, we found that for complete (100\%) mortality of eggs, about four times more methyl bromide was necessary, in comparison with the mobile stages. In an earlier work, Hartzer et al. (2010) reported that methyl bromide was generally more effective than sulfuryl fluoride in field assays for the control of eggs of the red flour beetle, Tribolium castaneum (Herbst) (Coleoptera: Tenebrionidae). Similar results have been reported by Small (2007) for the confused flour beetle, Tribolium confusum Jacquelin du Val (Coleoptera: Tenebrionidae), and the Mediterranean flour moth, Ephestia kuehniella Zeller (Lepidoptera: Pyralidae). However, there are not many reports on the efficacy of methyl bromide for the control of stored-product psocids. Pike (1994) reported that all life stages of L. entomophila were controlled by methyl bromide at a concentration of $50 \mathrm{mg} / \mathrm{liter} / \mathrm{h}$, which was considerably higher than the highest concentration used here $\left(0.616 \mathrm{~g} / \mathrm{m}^{3}(\mathrm{mg} /\right.$ liter $) /$ $48 \mathrm{~h}=0.0128 \mathrm{mg} /$ liter $/ \mathrm{h})$. Also, in that work, it was reported that $L$. entomophila was more susceptible than T. castaneum to methyl bromide, and it was concluded that, in general, concentrations that were effective for control of other stored-product insect pest species, such as beetles and moths, can be effective for L. entomophila (Pike 1994). Moreover, Rajendran (1994) reported that $L$. bostrychophila eggs were completely controlled at $1.3 \mathrm{mg} /$ liter after $24 \mathrm{~h}$ of exposure, which was again higher than the highest concentration 

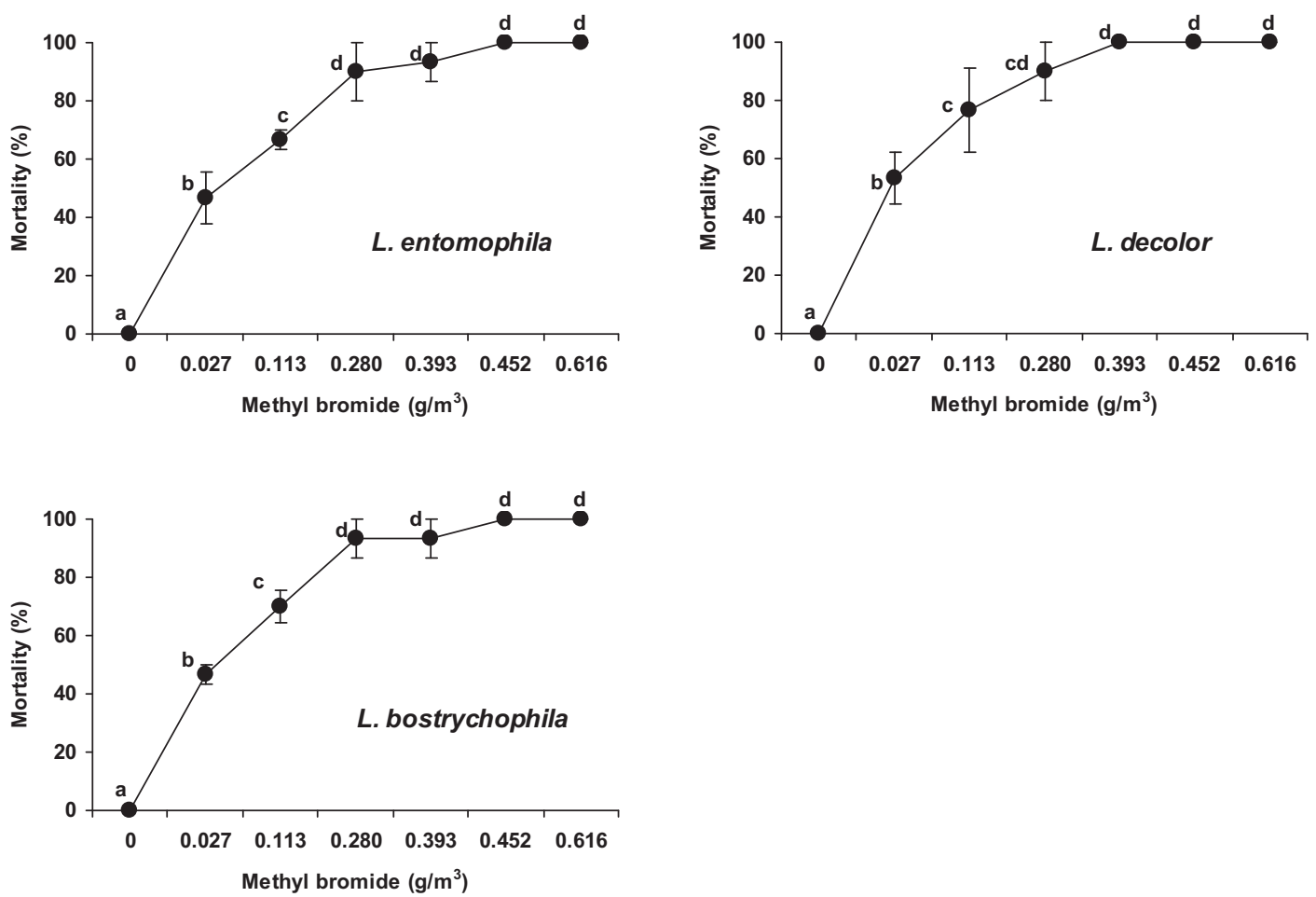

Fig. 3. Mortality (\% $\pm \mathrm{SE}$ ) of eggs of L. entomophila, L. decolor, and L. bostrychophila after a 48-h exposure to methyl bromide. Within each species, means followed by the same letter are not significantly different (HSD test at 0.05; for L. entomophila $F=41.0$, for $L$. decolor $F=24.6$, and for $L$. bostrychophila $F=72.69$; in all cases $\mathrm{df}=6.14$ and $P<0.001$ ).

Table 1. Probit estimates for mortality of eggs of the different species of psocids exposed to methyl bromide for $48 \mathrm{~h}$

\begin{tabular}{|c|c|c|c|c|c|c|}
\hline Psocid species & $\begin{array}{c}\mathrm{LC}_{50}\left(\mathrm{~g} / \mathrm{m}^{3}\right) \\
(95 \% \text { Conf. limits })\end{array}$ & $\begin{array}{c}\mathrm{LC}_{90}\left(\mathrm{~g} / \mathrm{m}^{3}\right) \\
(95 \% \text { Conf. limits })\end{array}$ & $\begin{array}{c}\mathrm{LC}_{99}\left(\mathrm{~g} / \mathrm{m}^{3}\right) \\
\text { (95\% Conf. limits) }\end{array}$ & Slope \pm SE & Intercept $\pm \mathrm{SE}$ & $\begin{array}{l}\chi^{2} \text { values } \\
(\mathrm{df}=16)\end{array}$ \\
\hline & & & & & & \\
\hline L. decolor & & & & & $-0.225 \pm 0.088$ & $29.16(P=0.0229)$ \\
\hline L. bostrychophila & $0.037(0.019-0.056)$ & $0.213(0.147-0.352)$ & $0.891(0.496-2.525)$ & $0.417 \pm 0.039$ & $1.119 \pm 0.032$ & $16.39(P=0.426)$ \\
\hline
\end{tabular}

in the current experiments. In our test, L. decolor was the most susceptible at the egg stage to methyl bromide as compared with L. entomophila and L. bostrychophila, but, for all three species, the highest doses of methyl bromide recorded for complete mortality were for the egg stage. However, psocids are known to exhibit a delay in their egg development as a mechanism of resistance to phosphine. Nayak et al. (2003) showed that duration of egg hatch was longer for a phosphine-resistant L. bostrychophila strain as compared with that of a phosphine-susceptible strain. Thus, the interval in which egg hatching was recorded in the current study ( $8 \mathrm{~d}$ ) might have concealed any possible delay in egg hatching.

Egg mortality is an issue of major importance for the application of gases for control of stored-product pests, as eggs are usually the most tolerant life stage to fumigants. It was reported that the susceptibility of eggs of the cheese mite, Tyrophagus putrescentiae (Schrank)
(Astigmata: Acaridae), varied according to the age of eggs, and that eggs that were 17-27 d old were less susceptible than others to methyl bromide (Barker 1967). For eggs of the same species, similar results have been reported by Phillips et al. (2008) for sulfuryl fluoride, given that T. putrescentiae eggs were able to survive at concentrations that exceeded three times the label concentration. For the same insecticide, Baltaci et al. (2009) reported that young eggs of the tobacco moth, Ephestia elutella (Hübner) (Lepidoptera: Pyralidae), were more sensitive to sulfuryl fluoride than older eggs. In our current study, we used eggs of mixed ages, although in most of the cases, the eggs were young because they were collected $1 \mathrm{~d}$ before the initiation of the experiments. Further testing is needed to clarify if egg age plays a role in the efficacy of methyl bromide for control of psocids.

Taking into account the data from our bioassays, we can conclude that, at least in the cases of 
L. entomophila, L. decolor, and L. bostrychophila, all life stages are controlled at $0.452 \mathrm{~g} / \mathrm{m}^{3}$, although significant mortality also can be caused at $0.393 \mathrm{~g} / \mathrm{m}^{3}$. These concentrations are high for a 48-h structural fumigation (Hartzer et al. 2010). Exposures for $24 \mathrm{~h}$ or even shorter duration should be evaluated, and at higher concentrations. Given that methyl bromide is still the only insecticide that is registered for quarantine and preshipment treatments for many commodities (e.g., cotton), a more thorough evaluation of this insecticide for this purpose is needed. However, most of the recent fumigation studies for stored products are focused on the use of alternatives to methyl bromide, despite the fact that methyl bromide will continue to play a role for quarantine purposes. Our results show that high concentrations of methyl bromide can be effective for the complete control of psocids after a 2-d period at $27.5^{\circ} \mathrm{C}$. These data can be utilized by applicators and phytosanitary inspectors when a methyl bromide treatment is planned.

\section{Acknowledgments}

We would like to thank Ann Redmon and Ngunza Kisangani for technical assistance. Mention of trade names or commercial products in this publication is solely for the purpose of providing specific information and does not imply recommendation or endorsement by the U.S. Department of Agriculture, the University of Thessaly, Kansas State University, or Rajshahi University. Partial funding for this work was provided by the Kansas Agricultural Experiment Station, for which this is manuscript 15-237-J, a grant from the U.S. Department of Agriculture (USDA) Methyl Bromide Transitions program, and support to M.M.H. from the Fulbright Foundation. USDA is an equal opportunity provider and employer.

\section{References Cited}

Athanassiou, C. G., F. H. Arthur, and J. E. Throne. 2009. Efficacy of grain protectants against four psocid species on maize, rice and wheat. Pest Manage. Sci. 65: 1140-1146.

Athanassiou, C. G., G. P. Opit, and J. E. Throne. 2010a. Effect of commodity characteristics on population growth of four stored-grain psocid pests (Psocoptera: Liposcelididae). J. Econ. Entomol. 103: 985-990.

Athanassiou, C. G., F. H. Arthur, and J. E. Throne. 2010 b. Efficacy of methoprene for control of five species of psocids (Psocoptera) on wheat, rice, and maize. J. Food Prot. 73: 2244-2249.

Athanassiou, C. G., T. W. Phillips, M. J. Aikins, M. M. Hasan, and J. E. Throne. 2012. Effectiveness of sulfuryl fluoride for control of different life stages of stored-product psocids (Psocoptera). J. Econ. Entomol. 105: 282-287.

Athanassiou, C. G., N. G. Kavallieratos, J. E. Throne, and C. T. Nakas. 2014. Competition among species of stored product psocids in stored grains (Psocoptera). PLoS ONE 9: e102867.

Baltaci, D., D. Klementz, B. Gerowitt, M. J. Drinkall, and C. H. Reichmuth. 2009. Lethal effects of sulfuryl fluoride on eggs of different ages and other life stages of the warehouse moth Ephestia elutella (Hübner). J. Stored Prod. Res. 45: 19-23.
Barker, P. S. 1967. Susceptibility of eggs of Tyrophagus putrescentiae (Schrank) (Astigmata: Acaridae) to methyl bromide. J. Stored Prod. Res. 2: 247-249.

Bonjour, E. L., G. P. Opit, J. Hardin, C. L. Jones, M. E. Payton, and R. L. Beeby. 2011. Efficacy of ozone fumigation against the major grain pests in stored wheat. J. Econ. Entomol. 104: 308-316.

Hartzer, M., B. H. Subramanyam, W. Chayaprasert, D. Maier, S. Savoldelli, J. F. Campbell, and P. W. Flinn. 2010. Methyl bromide and sulfuryl fluoride effectiveness against red flour beetle life stages, pp. 365-370. In M. O. Carvalho, P. G. Fields, C. S. Adler, F. H. Arthur, C. G. Athanassiou, J. F. Campbell, F. Fleurat-Lessard, P. W. Flinn, R. J. Hodges, and A. A. Isikber (eds.), Proceedings of the Tenth International Working Conference on Stored Product Protection, 27 June-2 July 2010, Estoril, Portugal. Julius Kühn-Institut, Berlin, Germany.

Kučerová, Z. 2002. Weight losses of wheat grains caused by psocid infestation. Plant Prot. Sci. 38: 103-107.

Nayak, M. K. 2006. Psocid and mite pests of stored commodities: small but formidable enemies, pp. 1061-1073. In I. Lorini, B. Bacaltchuk, H. Beckel, D. Deckers, E. Sundfeld, J. P. dos Santos, J. D. Biagi, J. C. Celaro, L. R. D'A. Faroni, L. de O. F. Bortolini, et al. (eds.), Proceedings of the 9th International Working Conference on Stored Product Protection, 15-18 October 2006. Brazilian Post-harvest Association ABRAPOS, Campinas, São Paulo, Brazil.

Nayak, M. K., and P. J. Collins. 2008. Influence of concentration, temperature and humidity on the toxicity of phosphine to the strongly phosphine resistant psocid Liposcelis bostrychophila Badonnel (Psocoptera: Liposcelididae). Pest Manage. Sci. 64: 971-976.

Nayak, M. K., P. J. Collins, and S. R. Reid. 1998. Efficacy of grain protectants and phosphine against Liposcelis bostrychophila, L. entomophila, and L. paeta (Psocoptera: Liposcelidae). J. Econ. Entomol. 91: 1208-1212.

Nayak, M. K., P. J. Collins, H. Pavic, and R. A. Kopittke. 2003. Inhibition of egg development by phosphine in the cosmopolitan pest of stored products Liposcelis bostrychophila (Psocoptera: Liposcelididae). Pest Manage. Sci. 59: 1191-1196.

Nayak, M. K., P. J. Collins, J. E. Throne, and J. J. Wang. 2014. Biology and management of psocids infesting stored products. Ann. Rev. Entomol. 59: 279-297.

Opit, G. P., and J. E. Throne. 2008a. Population growth and development of the psocid Lepinotus reticulatus at constant temperatures and relative humidities. J. Econ. Entomol. 101: 605-615.

Opit, G. P., and J. E. Throne. 2008b. Effects of diet on population growth of psocids Lepinotus reticulatus and Liposcelis entomophila. J. Econ. Entomol. 101: 616-622.

Opit, G. P., F. H. Arthur, J. E. Throne, and M. E. Payton. 2012. Susceptibility of stored-product psocids to aerosol insecticides. J. Insect Sci. 12: 1-14.

Phillips, T. W., M. M. Hasan, M. J. Aikins, and M. W. Schilling. 2008. Efficacy of sulfuryl fluoride to control ham mites and red-legged ham beetles. In Proceedings of the Annual International Research Conference on Methyl Bromide Alternatives and Emissions Reductions, 11-14 November 2008, Orlando, FL, Abstract 89.

Pike, V. 1994. Laboratory assessment of the efficacy of phosphine and methyl bromide fumigation against all life stages of Liposcelis entomophilus (Enderlein). Crop Prot. 13: $141-145$

Rajendran, S. 1994. Psocids in food commodities and their control. Pestology 28: 14-19.

Sekhon, R. K., M. W. Schilling, T. W. Phillips, M. J. Aikins, M. M. Hasan, and W. B. Mikel. 2010. Effects of phosphine 
and methyl bromide fumigation on the safety, volatile composition and sensory quality of dry cured ham. Meat Sci. 86: $411-417$.

Small, G. J. 2007. A comparison between the impact of sulfuryl fluoride and methyl bromide fumigations on stored-product insect populations in UK flour mills. J. Stored Prod. Res. 43: $410-416$.
(UNEP) United Nations Environment Programme. 1998.

Report of the Methyl Bromide Technical Options Committee, 1998. Assessment of Alternatives to Methyl Bromide. United Nations Environment Programme, Nairobi, Kenya.

Received 26 January 2015; accepted 11 March 2015. 